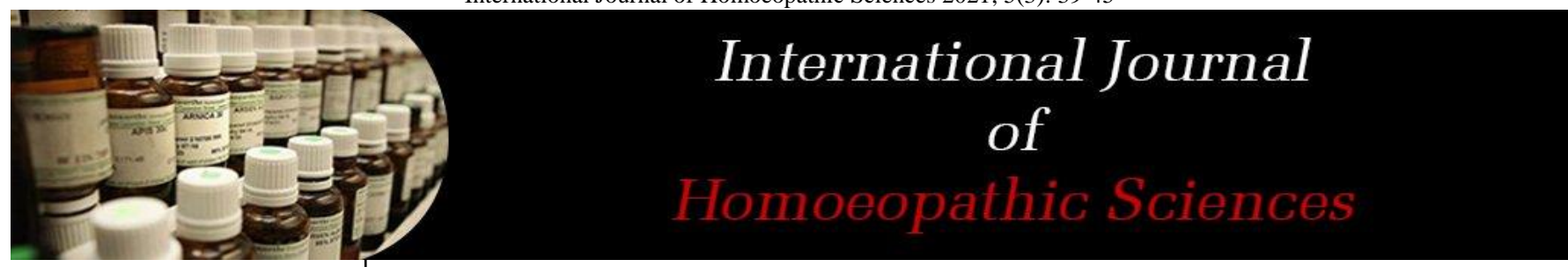

E-ISSN: 2616-4493

P-ISSN: 2616-4485

www.homoeopathicjournal.com

IJHS 2021: 5(3): 39-45

Received: 10-03-2021

Accepted: 30-04-2021

Dr. Gausia Sayed

Associate Professor, Department of

Case taking and Repertory, Smt.

Chandaben Mohanbhai Patel

Homeopathic Medical College,

Mumbai, Homeopathic OPD/IPD

Consultant at Shree Mumbadevi

Homeopathic Hospital, Vile Parle

West, Mumbai and Honorary

Consultant at Holy Spirit and

Shakuntala Memorial Hospital,

Andheri, East, Mumbai, India

Dr. Rupa Rao

Associate Professor and HOD,

Department of Community

Medicine, Smt. Chandaben

Mohanbhai Patel Homeopathic

Medical College, Mumbai,

Homeopathic OPD/IPD

Consultant at Shree Mumbadevi

Homeopathic Hospital, Vile Parle,

West, Mumbai, Maharashtra, India

Dr. Rakesh Gupta

Associate Professor, Department of

Forensic Medicine and Toxicology,

Smt. Chandaben Mohanbhai Patel

Homeopathic Medical College,

Mumbai, Homeopathic OPD/IPD

Consultant at Shree Mumbadevi

Homeopathic Hospital, Vile Parle

West, Mumbai, Maharashtra, India

Dr. Aavishkar Zagaday

Associate Professor, Department of

Physiology, Smt. Chandaben

Mohanbhai Patel Homeopathic

Medical College, Mumbai,

Homeopathic OPD/IPD

Consultant at Shree Mumbadevi

Homeopathic Hospital, Vile Parle

West, Mumbai, Maharashtra, India

Dr. Twynta Fernando

Intern at Smt. C.M.P.

Homeopathic Medical College, Vile

Parle West, Mumbai, Maharashtra,

India

Eesha Kothari

Intern at Smt. C.M.P.

Homeopathic Medical College, Vile

Parle West, Mumbai, Maharashtra,

India

Corresponding Author:

Dr. Gausia Sayed

Associate Professor, Department of

Case taking and Repertory, Smt.

Chandaben Mohanbhai Patel

Homeopathic Medical College,

Mumbai, Homeopathic OPD/IPD

Consultant at Shree Mumbadevi

Homeopathic Hospital, Vile Parle

West, Mumbai and Honorary

Consultant at Holy Spirit and

Shakuntala Memorial Hospital,

Andheri, East, Mumbai, India

\section{Role of anti-miasmatic remedy in case of alopecia areata}

\author{
Dr. Gausia Sayed, Dr. Rupa Rao, Dr. Rakesh Gupta, Dr. Aavishkar \\ Zagaday, Dr. Twynta Fernando and Dr. Eesha Kothari
}

DOI: $\underline{\text { https://doi.org/10.33545/26164485.2021.v5.i3b.405 }}$

\begin{abstract}
Hair is an epidermal appendage, composed of a protein called keratin. The hair follicle supports the hair shaft and regulates its growth. Around 100 strands of hair are lost everyday due to the hair growth cycle. Excessive loss of hair is termed as Alopecia. Alopecia areata affects nearly $2 \%$ of the general population at some point during their lifetime. Though hair has hardly any functional attributes in humans, alopecia is not only a great cosmetological concern but also a psychological trauma!

The Case below demonstrates the Homoeopathic Management of Alopecia Areata in a 6 year old patient, with a positive family history of the same, who had previously taken allopathic medicines, without much improvement in his condition. Integrated knowledge of Trichology paves way for Individualistic Homoeopathic Remedy Selection and its application through Clinical Training.
\end{abstract}

Keywords: Alopecia, alopecia Areata, trichology, hereditary, baldness, homoeopathic constitutional remedy, tuberculinum, calcarea phosphorica

\section{Introduction}

Growth of hair is cyclic. Under normal conditions $85-95 \%$ hair are in anagen phase (growth phase), $1 \%$ in catagen (phase of decay) and $4-14 \%$ in the telogen phase (resting phase). Hair loss can be broadly classified into two types-a) Non-scarring Alopecia (Temporary hair loss and the scalp skin looks normal) and b)Scarring or Cicatrical Alopecia (Permanent hair loss in which the scalp is devoid of follicular openings).

ALOPECIA AREATA is an autoimmune disorder which manifests as patchy loss of hair due to sudden precipitation of a group of contiguous hair follicles into telogen (Resting phase). It is common in young adults, about $20 \%$ patients are children. It may or may not be associated with other autoimmune diseases. The essential basis is cessation of hair growth with premature club-hair formation. Clinically, along with patchy hair loss, nail pits, ridges and transverse furrows can be seen as an association.

Pre-disposing factors causing baldness- 1. Genetic background 2.Large quantities of androgenic hormones

Triggering Factors: Emotional stress, Endocrine upset and Autoimmunity.

Morphology: Loss of hair in well defined rounded patches. Bald skin is smooth and lacks any sign of inflammation.. Spreading margins bear broken stubs of hair that taper towards the skin surface, are easily pluckable and show a rounded bulb (exclamation mark hair).

Distribution: Scalp is affected most often, alone or in combination with other regions. Beard, moustache, eyebrows, eyelashes, axillae, pubis or extremities are some other sites. Involvement of the whole scalp leading to complete baldness is termed as alopecia totalis. Complete loss of body hair is designated as alopecia universalis. Both these conditions have poor prognosis.

Effects of Testosterone on Hair: Testosterone causes growth of hair over pubis, face, chest, back, and along Linea Alba. It decreases the growth of hair on the top of the head. A man who does not have functional testes does not become bald.

Laboratory studies to evaluate non-scarring Alopecia: Complete blood cell count, Ferritin, 
Thyroid screening, Scalp biopsy, Microscopic examination of hair, Antinuclear Antibody, Hormones (e.g. dehydroepiandrosterone sulfate, testosterone, androstenedione), etc

\section{Clinical Case Presentation}

A 6 year old male patient was brought to the clinic with a complaint of multiple patchy loss of hair on scalp, since 1 year,which aggravated Since 6 months. No itchiness of scalp. He had taken allopathic treatment for the same without much improvement.

The progression of the bald patches: Left Occipital $\rightarrow$ Right Occipital $\rightarrow$ Right Temporal $\rightarrow$ Left Temporal $\rightarrow$ Vertex No specific cause traced. No characteristic sensation or modality present.

\section{Clinical Appearance}

(Before treatment: 30-11-2019)

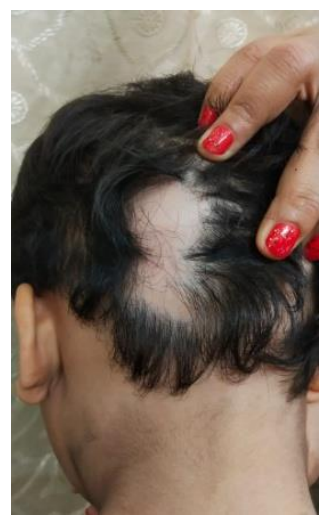

Fig 1: Bald patch in left occipital region

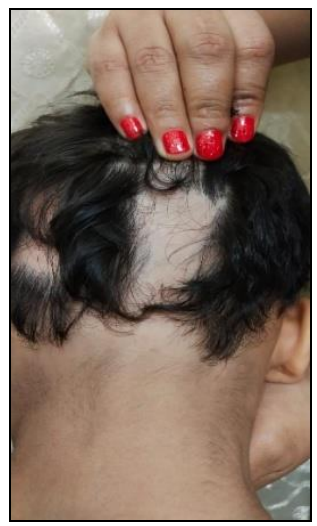

Fig 2: Bald patch in right occipital region

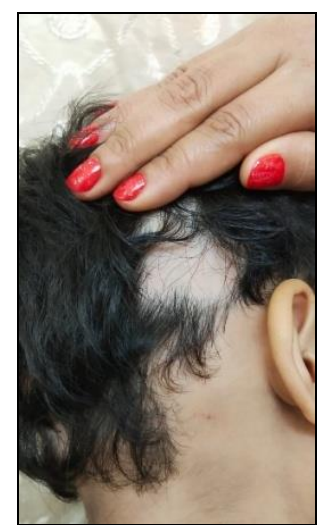

Fig 3: Bald patch in right temporal region

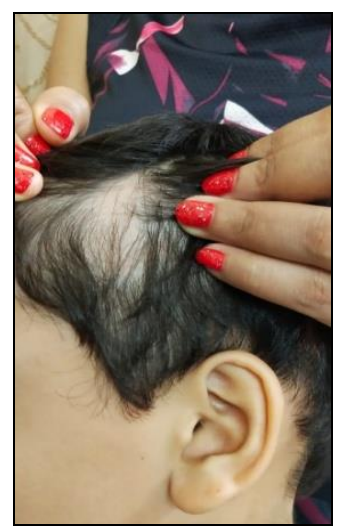

Fig 4: Bald patch in left temporal region

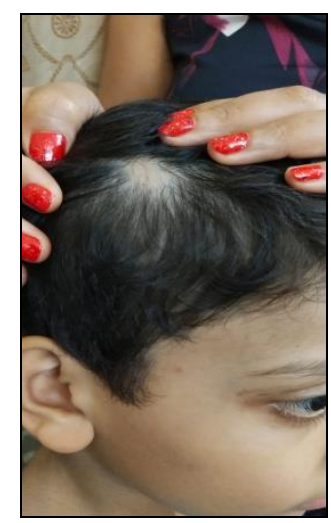

Fig 5: Bald patch in vertex

\section{Physical Generals}

- Appearance - Fair complexion, lean constitution and delicate features.

- Likes- Sweets

- Perspiration- Profuse

- $\mathrm{H} / \mathrm{O}$ - Enuresis

\section{Mental Characteristics}

- Irritability

- Restlessness - cannot sit in one place, fidgety.

- Sympathetic

- Likes to roam around. Wants to visit new places.

- Mischievous.

- Fear of dark

\section{Family History}

- Father -Alopecia Areata In Childhood.

- Mother- Asthma in childhood; At present: K/C/O Hypothyroidism

- Elder brother- G6PD deficiency

- Paternal Grandparents- Hypertension.

- Maternal Grandparents- Hypertension + Diabetes Mellitus

Examination findings: O/E: General Condition Fare.

Throat, R.S., C.V.S., G.I.T., C.N.S. - No Abnormality Detected.

\section{Clinical Diagnosis: Alopecia Areata}

Pathological understanding in cases of Alopecia Areata: Genome-Wide Association Studies(GWAS) analysis in humans have identified 14 genetic loci associated with alopecia areata. One locus, in particular, harboring the genes encoding the natural killer (NK) cell receptor D ligands and 
retinoic acid early transcript $1 \mathrm{~L}$ protein, is found to be involved in alopecia areata and not in other autoimmune diseases. According to functional studies $\mathrm{CD} 8^{+} \mathrm{NKG} 2 \mathrm{D}^{+} \mathrm{T}$ cells play an important role in AA disease pathogenesis.Gene expression profiling studies have revealed predominant signatures of the Interferon gamma pathway and its related cytokines, and also, cytotoxic $\mathrm{T}$ cells, both of which are mediated by Janus kinase as their downstream effectors.

Homoeopathic understanding: Dynamic Chronic Miasmatic disease with fully developed symptoms. Predominant Miasm - Tubercular

Prognosis and complications: The potential for hair regrowth remains since the hair follicles are not damaged.Spontaneous regrowth of hair is seen in $60-70 \%$ cases and occurs as a rule in patients with one or two patches of short duration (less than 6 months). The prognosis varies widely, and poor outcomes are associated with an early age of onset, extensive loss, the ophiasis variant, nail changes, a family history, or comorbid autoimmune disorders. No complications as such other than disease progression.

\section{Treatment Strategy}

1. Conventional line of treatment: Treatment in allopathy includes Topical steroids, Intralesional steroids, Topical or Systemic PUVA therapy,Topical Dinitrochlorobenzene(DNCB).

2. Homeopathic line of treatment: As per Aphorism 5: "The ascertainable physical constitution of the patient (especially when the disease is chronic), his moral and intellectual character, his occupation, mode of living, and habits, his social and domestic relations, his age, sexual function etc., are to be taken into consideration"

As per Aphorism 190: “All true medical treatment of a disease on the external parts of the body that has occurred from little or no injury from without,must therefore, be directed against the whole, must effect the annihilation and cure of the general malady by means of internal remedies, if it is wished that the treatment should be judicious, sure, efficacious and radical."

Homoeopathic Approach In Cases Of Alopecia - Holistic approach- Persons constitution i.e. his Mind, Physical general and Physical particular symptoms are taken into consideration according to Aphorism 5.

\section{Susceptibility}

High Susceptibility due to following reasons:

1. Symptom similarity

2. Many characteristics at the level of mentals and generals.

3. No structural changes

4. Reversible disease

5. Young age male patient

6. Good nutritional status

7. Good Sensitivity

Totality of symptoms: According to Kentian Approach.

1. Fear of dark

2. Irritability
3. Restlessness

4. Sympathetic

5. Desires to wander around

6. Perspiration Profuse

7. Likes Sweets

8. Lean personality

9. Hairfall in spots

\begin{tabular}{l}
$\square$ MIND, FEAR (apprehension, dread), dark, of \\
$\square$ MIND, IRRITABILITY, children, ... \\
$\square$ MIND, RESTLESSNESS, children, ... \\
$\square$ MIND, SYMPATHY, compassion, ... \\
$\square$ MIND, WANDER, desires to, ... \\
$\square$ HEAD, HAIR, falling, ... \\
$\square$ HEAD, HAIR, falling, spots, in, ... \\
$\square$ PERSPIRATION, PROFUSE, ... \\
$\square$ GENERALITIES, FOOD, sweets, desire for, ... \\
$\square$ GENERALITIES, LEAN people \\
\hline
\end{tabular}

Fig 6: Repertorial Totality (Homoeopathic Repertory App)

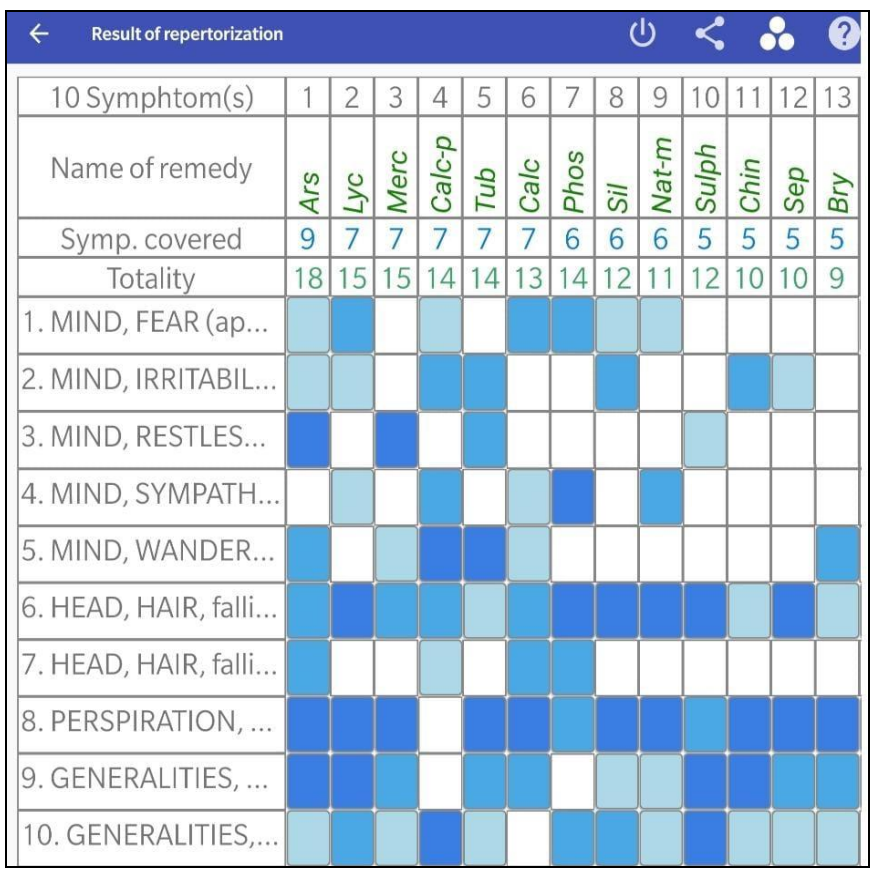

Fig 7: Repertorization (Homeopathic Repertory App)

Remedy Selection: Tuberculinum 200 (1P) and CalcareaPhosphorica 200 t.d.s X 7 Days

\begin{tabular}{|c|c|c|}
\hline Date & Follow Up & Prescription \\
\hline $30 / 11 / 2019$ & $\begin{array}{c}1^{\text {st }} \\
\text { Prescription }\end{array}$ & $\begin{array}{c}\text { Tuberculinum 200 (1P) } \\
\text { CalcareaPhosphorica 200 t.d.s. } x \text { 7 days }\end{array}$ \\
\hline $09 / 12 / 2019$ & $>$ & SL 200 t.d.s. x 7 days \\
\hline $20 / 12 / 2019$ & SQ & $\begin{array}{c}\text { CalcareaPhosphorica 1M (1P) } \\
\text { Tuberculinum 1M t.d.s. x 7 days }\end{array}$ \\
\hline $02 / 01 / 2020$ & $>>$ & Tuberculinum 1M t.d.s. x 7 days \\
\hline $09 / 01 / 2020$ & $>>$ & SL 200 t.d.s. x 7 days \\
\hline $27 / 01 / 2020$ & $>>60 \%$ & Tuberculinum 1M t. d. s. x 7 days \\
\hline $04 / 02 / 2020$ & $>>$ & SL 200 t.d.s. x 1 month \\
\hline $20 / 04 / 2020$ & $>>80 \%$ & SL 200 t.d.s. x 1 month \\
\hline $22 / 05 / 2020$ & $>>$ & SL 200 t.d.s. x 1 month \\
\hline $20 / 06 / 2020$ & $>>100 \%$ & SL 200 t.d.s. x 1 month \\
\hline
\end{tabular}




\section{Prescription based on}

Holistic Approach i.e. Constitutional remedy followed by frequent repetition of Anti-miasmatic remedy.

Reference

momentarily; has a constant desire to change, and travel, and ฐo
somewhere, and do something different, or to find a new doctor. The
desire to travel, that cosmopolitan condition of the mind belongs so
strongly to the one who needs Tuberc. It comes out so often in clini-
cal experience, is tound so often in the Calcareas, and especially in
Calc. phos., always wanting to go somewhere. Such is the condition
or those about to go into insanity, about to go into some lingering dis-

Fig 8: Lectures On Homoeopathic Materia Medica By Dr. James Tyler Kent- Indian Edition - Tuberculinum- Page 951

to go into phthisis have many times been cured by Calcarea. The relationship between Tuberc. and Calc. is very close. They are interchangeable; that is, the one may be indicated for a while, and then the other. They are both deep-acting remedies-also Silica is closely related to Tuberc., on the same plane of action, going deep into the life in a similar way; Calcarea, Tuberc. and Silica, and the Silicates.

Fig 9: Lectures On Homoeopathic Materia Medica By Dr. James Tyler Kent - Indian Edition - Tuberculinum- Page 952

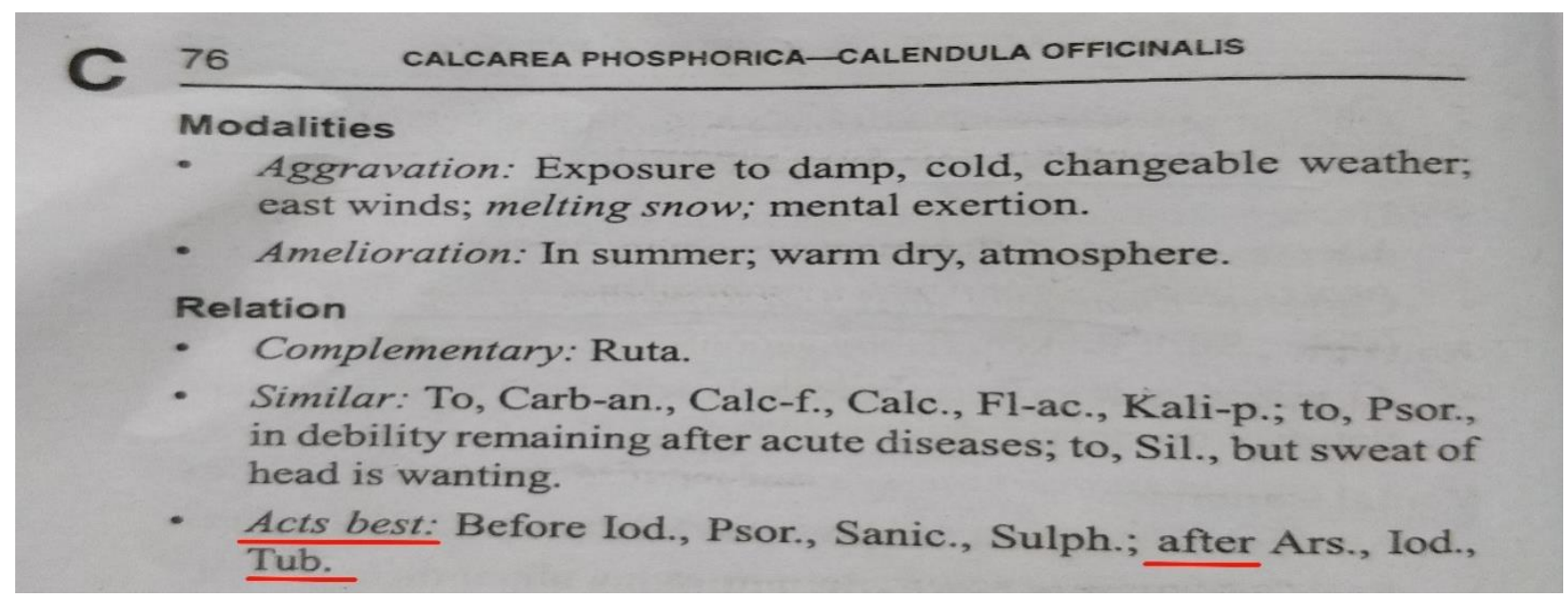

Fig 10: Allen's Keynotes Rearranged And Classified With Leading Remedies Of The Materia Medica and Bowel Nosodes By Dr.H.C.Allen- Tenth Edition-CalcareaPhosphorica- Page 76

Relations
(Burnett recommends to give the
Tuberculinum high if there is a strong
tubercular element in the case, if that element
is small, 30 is better.) Compare: Bacillinum
(including Tuberculinum of Swan), Bacil. test.,
Aviaire. In tubercular meningitis, lodof.
Irregular distribution of circulation,
constitutional remedy, Sul. Analogous
constitutional remedies, Pso., Med., Syph.,
Thuja. Sensation of an iron band compressing
brain (Thuj. Phthisis, insanity, Thyroid. Pain in
region of appendix, Iris. t., Ars., Lach. Pains in
breasts at menses, Con., Calc. Compatible:
Hydrast., "it actually seems to fatten up
tuberculous patients" (Burnett, confirmed by
Nebel), Calc., Calc-i., Calc-p., Phos., Thuj., Sep.,
Puls. Sensitive to music, Aco., Amb., Nat-c.,
Nux- v., Ph-ac., Sep., Thuj., Viol-o. (Better by
music, Trn.).

Fig 11: Dictionary Of Practical Materia Medica By Clarke J.H.- Tuberculinum - HompathFireFly App 


\section{Outer Head}

Sore pain; drawing, rending, tearing in the skull bones worse along the sutures.

Skull soft and thin; crackling noise like paper when pressed, mostly in the occiput.

Delayed closure, or re-opening of fontanelles.

Crawling over the top of head, as if ice were lying over the occiput; head hot; smarting of roots of the hair.

Itching black scurfs; poor crop of hair, or losing the hair.

Fig 12: Condensed Materia Medica By Dr. Hering C.-CalcareaPhosphorica- HompathFireFly App
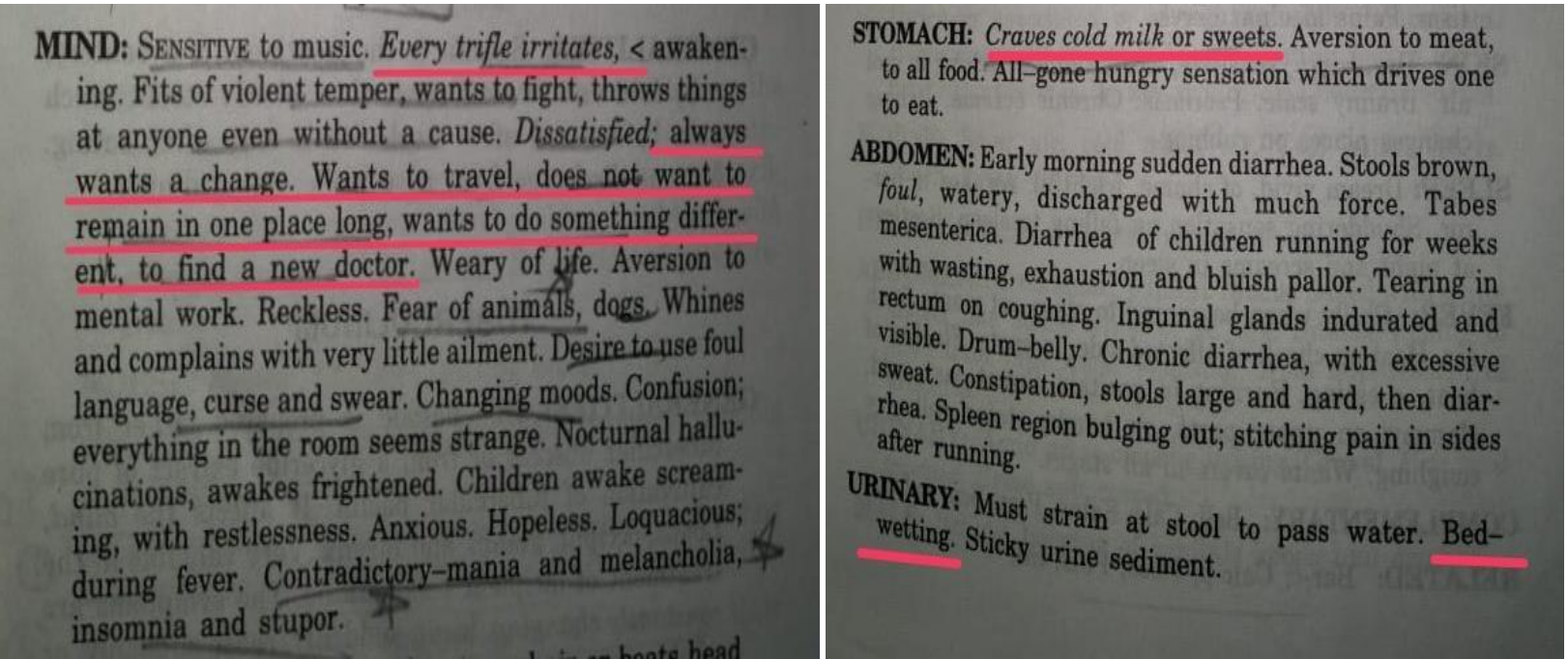

Fig 13: Materia Medica of Homoeopathic Medicines By Dr. S.R. Phatak - Second Edition -Revised and Enlarged - Tuberculinum-Page 718 and 719

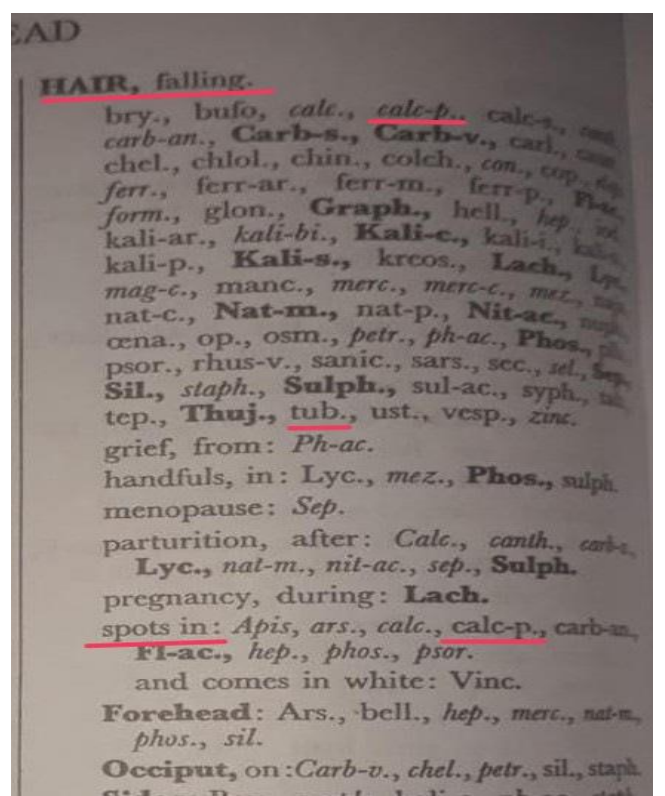

Fig 14: Repertory of the Homoeopathic Materia Medica By Dr. James Tyler Kent - Enriched Indian Edition - Page 120 


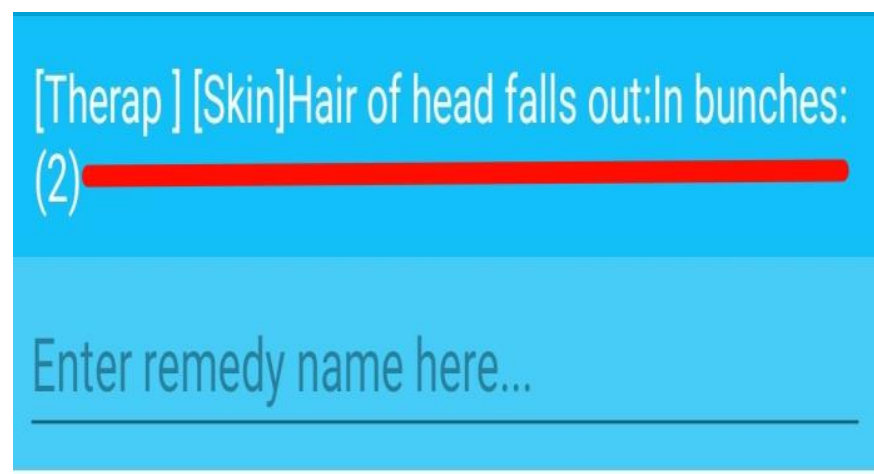

\section{2: Calc-p 3: Phos}

Fig 15: Therapeutic Pocket Book By Clemens Von Boenninghausen - HompathFireFly App

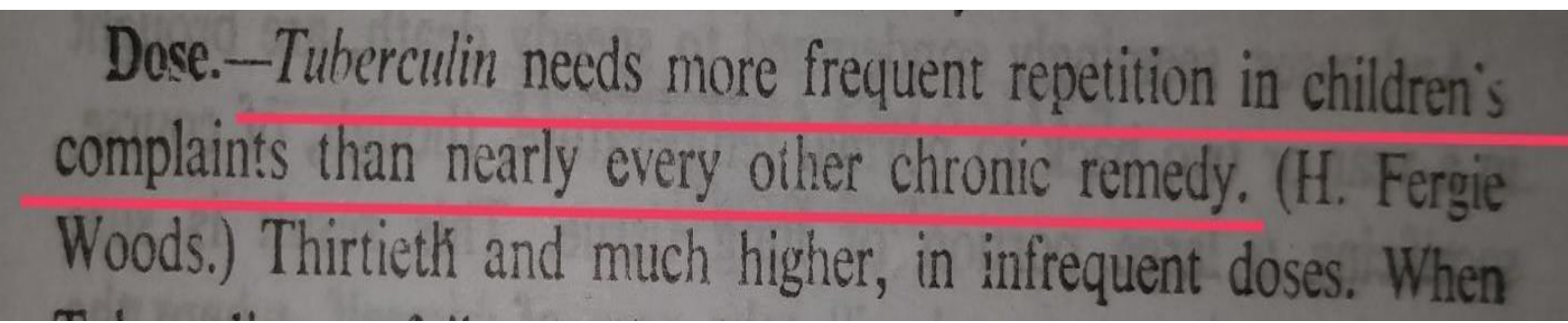

Fig 16: Pocket Manual Of Homoeopathic Materia Medica with Indian Medicine And Repertory By Dr. William Boericke - Ninth Edition Tuberculinum- Page 657

- As given in Boericke's Materia Medica, frequent repetition of Tuberculinum was administered to the patient to establish permanent cure.

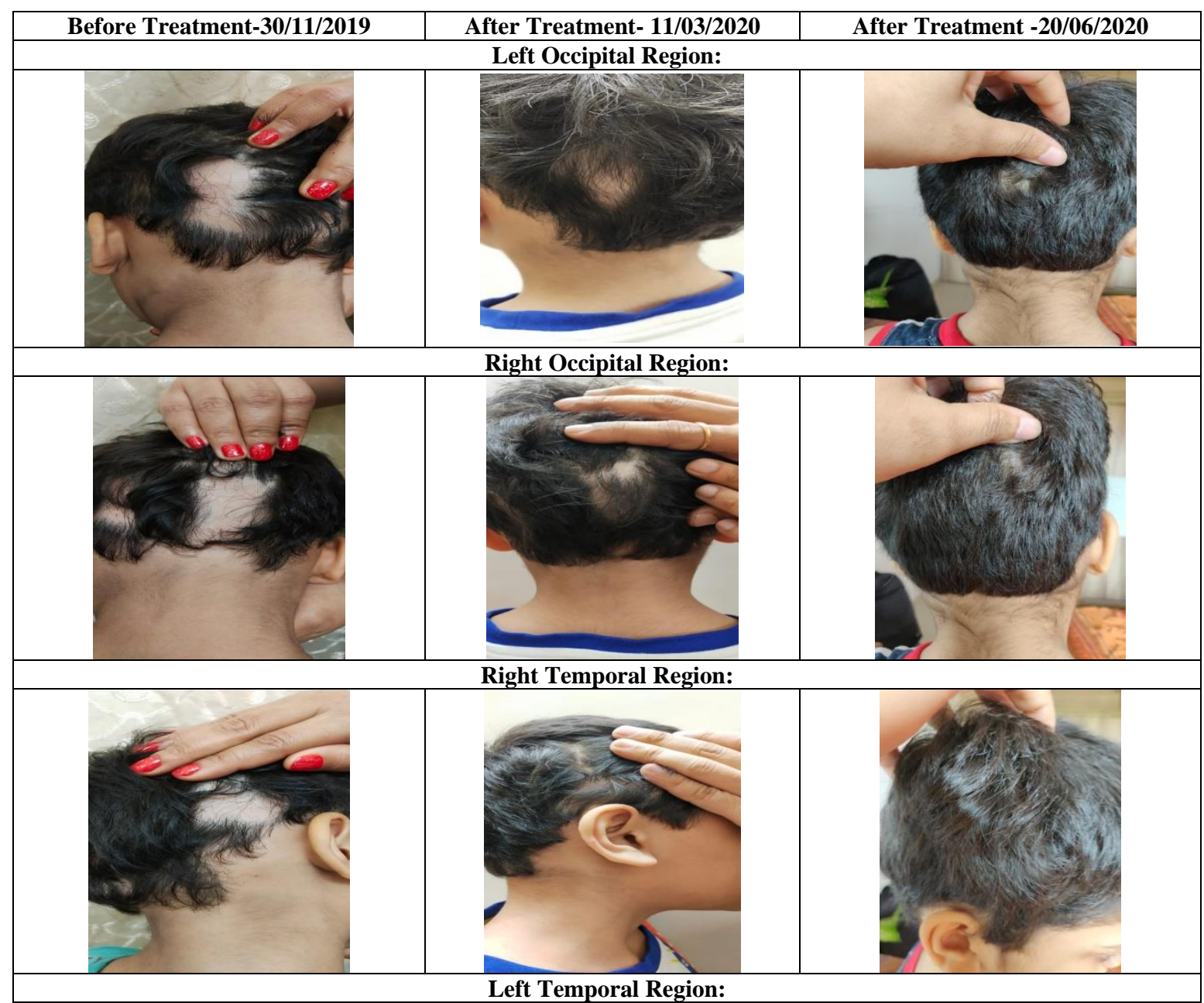




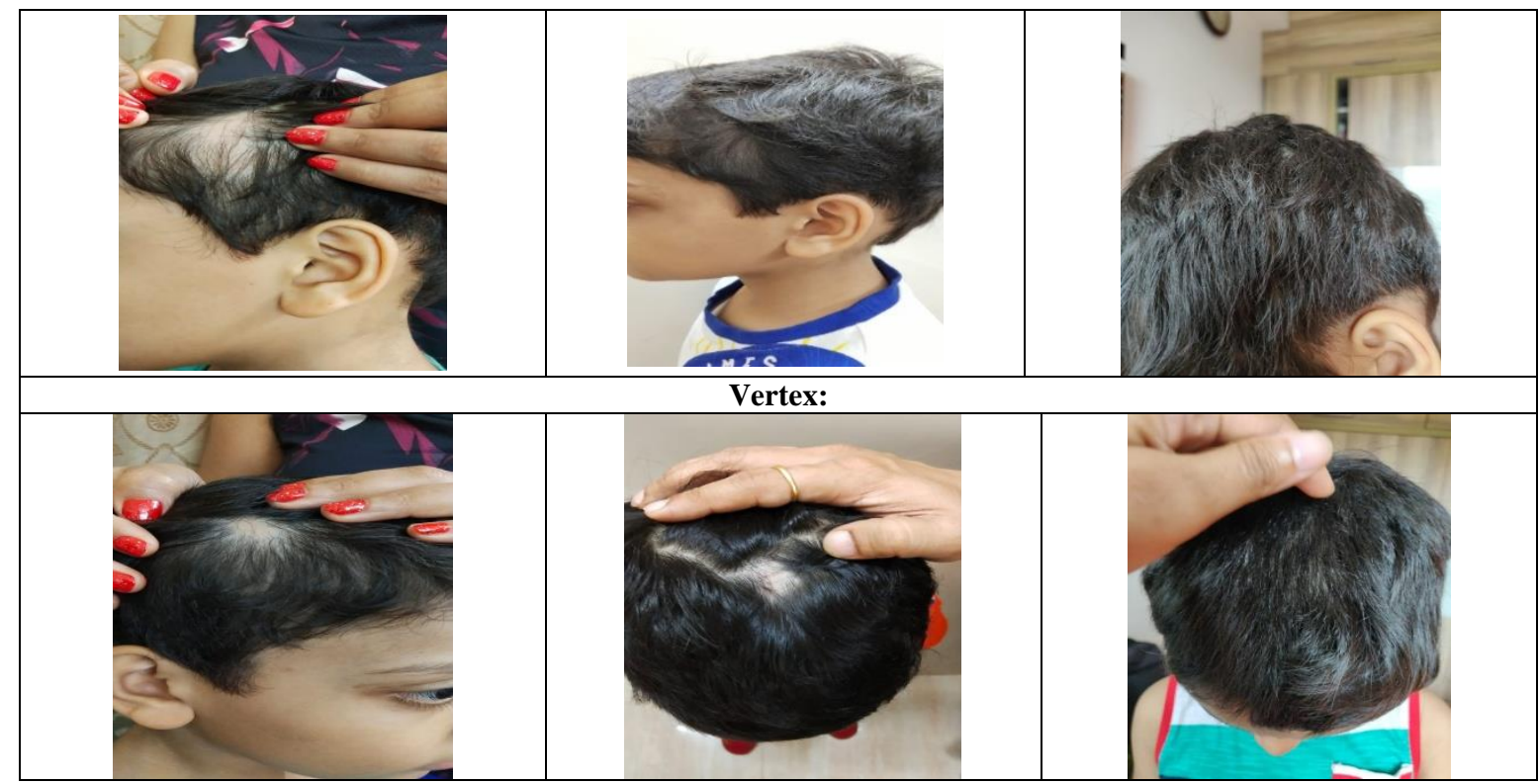

\section{Acknowledgement}

A heartful and sincere gratitude to Smt. C.M.P. Homeopathic Medical College and Hospital and Holy Spirit Hospital. We would also like to thank Dr. Mohanbhai Patel, Chairman, The Homeopathic Education Society, Vile Parle west, Mumbai. Dr. Asmita Parikh, General Secretary, The Homeopathic Education Society, Vile Parle (west), Mumbai. Dr. Parizad Damania, The Principal, Smt. C.M.P. Homeopathic Medical college, Vile Parle (west), Mumbai.

Case Learning: In cases of Alopecia, poor outcomes are associated with family history. This case helps us to understand that an appropriate Anti-miasmatic remedy given along with the constitutional remedy can cure conditions which have a familial tendency. The antimiasmatic remedy corrects the miasm through which the condition has been passed on from one generation to another and establishes permanent cure. We also learn that Tuberculinum being a Nosode and a deep acting remedy can be given in frequent doses in children as given in Pocket Manual of Homoeopathic Materia Medica by Dr. William Boericke. This case demonstrates the importance of a Holistic approach and treating the Man in disease and not the Disease in man, as said by Dr. J.T. Kent.

\section{Reference}

1. Dr. Uday Khopkar. Skin Diseases and Sexually Transmitted Infections, Seventh Edition 2019,186-187. ISBN: 978-93-8810845-4.

2. Dr. Siddharth N Shah. API textbook of Medicine, Seventh edition-Revised Reprint 2006, 1320-1321. ISBN:81-87540-28-1.

3. Dr. Parveen Kumar, Dr. Michael Clarke. Kumar and Clark's Clinical Medicine, Eighth Edition 2012, 1232. ISBN:978-0-7020-4500-4.

4. Dr. Arthur C Guyton, Dr. John E Hall. Textbook of Medical Physiology, Eleventh Edition 2006, 10041005. ISBN-10: 81-8147-920-3.

5. Dr. Brian J Hall, Dr. John C Hall. Sauer's Manual of Skin Diseases. Tenth Edition. Page No. 340. Reddy SR. Effect of homoeopathic medicine Lycopodium clavatum in urinary calculi. International Journal of Applied Research. 2010, 2017;3(1):790-1. ISBN-10: 1-

\section{7-077-5.}

6. Dr. Samuel Hahnemann. Organon of Medicine, Translated with preface by William Boericke, Sixth Edition. Reprint edition 2015;91:220. ISBN:81-7467202-8-Book Code No.:IB0405.

7. Dr. James Tyler Kent, Lectures on Homoeopathic Materia Medica, Incorporating the Materia Medica of the New Drugs from the Author's New Remedies, Indian Edition. 951, 952.

8. Dr. Allen HC. Allen's Keynotes Rearranged and Classified with Leading Remedies of the Materia Medica and Bowel Nosodes, Tenth Edition. 2005, 76. ISBN: 978-81-319-0088-8.

9. Dr.Clarke JH, Dictionary of Practical Materia Medica, Tuberculinum-From Hompath Fire Fly Mobile App.

10. Dr. William Boericke. Pocket Manual of Homoeopathic Materia Medica with Indian Medicine and Repertory, Ninth Edition-Revised and Enlarged with the addition of a Repertory by Oscar. E. Boericke. 2014, 657. ISBN: 81-7467-043-3. Book Code No.: IB0135.

11. Dr. Phatak SR Materia Medica of Homoeopathic Medicines. Second Revised and Enlarged Edition. 1999;718-719.-ISBN:978-81-319-0002-4.

12. Dr. Hering C, Condensed Materia Medica, Calcarea Phosphorica.-From Hompath Fire Fly Mobile App

13. Dr. James Tyler Kent. Repertory of the Homoeopathic Materia Medica. Enriched Indian Edition reprinted from Sixth American Edition. Edited and Revised by Clara Louise Kent 2002, 120. ISBN:978-81-319-01236.

14. Dr. Clemens Von Boenninghausen. Therapeutic Pocket Book. From Hompath Fire Fly Mobile App C. Herbert Pratt, Lloyd E.King, Jr., Andrew G. Messenger, Angela M.Christiano, John P. Sundberg. (2017).Alopecia Areata. Nat. Rev. Dis. Primers.Author manuscript; available in PMC 2017 Published online 2017 March 16.PMCID: PMC5573125.NIHMSID: NIHMS892973. PMID: 28300084.DOI: 10.1038/nrdp.2017.11.https://w ww.ncbi.nlm.nih.gov/pmc/articles/PMC5573125/

15. Repertorization Software App-Homeopathic Repertory App 